\title{
MAL-ESTAR DOCENTE E POLÍTICAS DE FORMAÇÃO PEDAGÓGICA
}

\author{
MALESTAR DE ENSEÑANZA Y POLÍTICAS DE FORMACIÓN PEDAGÓGICA
}

\author{
TEACHING MALAISE AND PEDAGOGICAL TRAINING POLICIES
}

\author{
Altair Alberto Fávero ${ }^{1}$ \\ https://orcid.org/0000-0002-9187-7283 \\ Camila Chiodi Agostini \\ http://orcid.org/0000-0002-7501-9553 \\ Larissa Morés Rigoni ${ }^{3}$ \\ http://orcid.org/0000-0001-9466-1595
}

\begin{abstract}
Resumo
O presente trabalho tem por objetivo analisar as políticas de formação pedagógica como possível alternativa para enfrentar o mal-estar docente. A hipótese defendida é a de que os diversos problemas que o professor enfrenta no exercício da docência geram a situação de um mal-estar e as políticas de formação pedagógica podem se tornar promissoras para seu enfrentamento. $\mathrm{O}$ texto toma emprestado o conceito freudiano de "mal-estar", atualizado pelo pensador brasileiro Sérgio Paulo Rouanet (1993). O artigo procura perseguir a seguinte questão: os problemas enfrentados na docência que hoje causam o mal-estar docente podem encontrar nas políticas de formação pedagógica uma alternativa de enfrentamento? Trata-se de um estudo qualitativo, exploratório e bibliográfico, ancorado no método analítico-hermenêutico. Na primeira seção do texto será reconstruído o conceito de mal-estar apresentado por Freud (1997) na obra O mal-estar na civilização; na segunda seção, esse mesmo conceito é abordado a partir dos escritos de Rouanet (1993), o qual analisa o mal-estar da modernidade; a terceira seção investiga o mal-estar docente a partir dos estudos do educador espanhol José Manuel Esteve (1999); por fim, na última seção são propostas algumas estratégias de superação do mal-estar docente por meio da ideia de políticas de formação pedagógica. Após o estudo realizado, concluímos que há muita dificuldade para lidar com o mal-estar docente gerado pelas situações enfrentadas pelos docentes na atualidade, o que pode
\end{abstract}

\footnotetext{
1 Doutor em Educação pela Universidade Federal do Rio Grande do Sul. Professor do Programa de PósGraduação em Educação da Universidade de Passo Fundo. Coordenador do Grupo de Estudos e Pesquisas em Educação Superior (GEPES - UPF/RS). E-mail: altairfavero@gmail.com

${ }^{2}$ Doutoranda em Educação no PPGEdu/UPF. Servidora Pública Federal da Universidade Federal da Fronteira Sul, UFFS, Campus Passo Fundo. E-mail: camila.chiodi.agostini@gmail.com

${ }^{3}$ Especialista em Gestão Escolar pela Uniasselvi. Professora de Educação Infantil no município de Paraí/RS e professora de Ensino Fundamental I no Colégio Mater Amabilis - Rede Sagrado de Educação, Nova Araçá/RS. Grupo de Estudos e Pesquisas em Educação Superior (Gepes - UPF/RS). E-mail: moreslarissa@gmail.com
}

\section{Como referenciar este artigo:}

FÁVERO, A. A.; AGOSTINI, C. C.; RIGONI, L. M. Mal-estar docente e políticas de formação pedagógica. Revista Pedagógica, v. 23, p. 1-27, 2021. 
ser amenizado se aliado a forças e atitudes conscientes, tanto da parte dos docentes como da gestão, incluindo políticas públicas de formação inicial e continuada.

Palavras-Chave: Políticas de formação pedagógica. Mal-estar docente. Modernidade. Crise educacional.

\title{
Resumen
}

El presente trabajo tiene como objetivo analizar las políticas de formación pedagógica como posible alternativa para enfrentar el malestar docente. La hipótesis que se defiende es que los diversos problemas que enfrenta el docente en el ejercicio de la docencia generan la situación de malestar y las políticas de formación pedagógica pueden volverse prometedoras para enfrentarlos. El texto toma prestado el concepto freudiano de "malestar", actualizado por el pensador brasileño Sergio Paulo Rouanet (1993). El artículo intentará acechar a la siguiente pregunta: ¿los problemas que se enfrentan en la docencia que hoy provocan el malestar docente pueden encontrar en las políticas de formación pedagógica una alternativa de afrontamiento? Se trata de un estudio cualitativo, exploratorio y bibliográfico, anclado en el método analítico-hermenéutico. En la primera sección del texto, se reconstruirá el concepto de malestar presentado por Freud (1997) en la obra El malestar en la civilización; en la segunda sección, este mismo concepto se aborda a partir de los escritos de Rouanet (1993), que analiza el malestar de la modernidad; la tercera sección investiga el malestar docente a partir de los estudios del educador español José Manuel Esteve (1999); finalmente, en el último apartado, se proponen algunas estrategias para afrontar el malestar docente a través de la idea de políticas de formación pedagógica. Tras el estudio, concluimos que existe mucha dificultad para afrontar el malestar docente generado por las situaciones que afrontan los docentes en la actualidad, el cual puede aliviarse si se combina con fuerzas y actitudes conscientes, tanto por parte de los docentes como de la dirección, pública. políticas de formación inicial y continua.

Palabras clave: Legislación educativa. Formación pedagógica. Malestar docente. Modernidad. Crisis educativa.

\begin{abstract}
The present work aims to analyze the pedagogical training policies as a possible alternative to face teacher malaise. The hypothesis defended is that the various problems that the teacher faces in the exercise of teaching generate the situation of malaise and the pedagogical training policies can become promising to face them. The text borrows the Freudian concept of "malaise", updated by the Brazilian thinker Sergio Paulo Rouanet (1993). The article will try to stalk the following question: can the problems faced in teaching that today cause teacher malaise find in the pedagogical training policies an alternative to cope? It is a qualitative, exploratory and bibliographic study, anchored in the analytical-hermeneutic method. In the first section of the text, will be rebuilt the concept of malaise presented by Freud (1997) in the work The malaise in civilization; in the second section, this same concept is approached from the writings of Rouanet (1993), which analyzes the malaise of modernity; the third section investigates teacher malaise based on the studies of the Spanish educator José Manuel Esteve (1999); finally, in the last section, some strategies for coping with teacher malaise are proposed through the idea of pedagogical training policies. After the study, we concluded that there is a lot of difficulty in dealing with the teacher malaise generated by the situations faced by teachers today, which can be alleviated if combined with conscious
\end{abstract}

\section{Como referenciar este artigo:}

FÁVERO, A. A.; AGOSTINI, C. C.; RIGONI, L. M. Mal-estar docente e políticas de formação pedagógica. Revista Pedagógica, v. 23, p. 1-27, 2021. 
forces and attitudes, both on the part of teachers and management, including public policies for initial and continuing training.

Keywords: Education Legislation. Pedagogical Training. Teacher malaise. Modernity. Education Crisis.

\section{INTRODUÇÃO}

A formação do profissional da educação é um dos grandes desafios no nosso tempo. As discussões fomentadas pelo tema, perpassam situações que envolvem desde a percepção do próprio docente, diante de sua atuação e formação, quanto aquelas voltadas a existência ou não de políticas públicas específicas que disciplinem essa construção de conhecimentos para o trabalho. Em tempos incertos como o que vivemos, talvez um dos aspectos mais intrínsecos ressalte sobre a incerteza do docente frente a sua atuação em sala de aula, diante de uma formação que aparentemente se expressa de forma apurada e fragilizada em tempos de educação voltada ao capital.

É nesse contexto que se observa que os educadores, empurrados para a desagregação e desarticulação no interior da sua própria profissão, necessitam realizar um processo de autoconhecimento e identificação dos problemas que enfrentam no exercício da docência. Esse exercício se transforma em peça fundamental na conjuntura atual, inclusive para prepará-los aos desafios do cotidiano e mitigar sentimentos e danos psicológicos que se mostram cada vez mais frequentes. Neste cenário, acreditamos que as formações, tanto iniciais quanto continuadas se tornam imprescindíveis.

O presente texto, ancorado nos estudos de Freud (1997), Rouanet (1993) e Esteve (1999), Consaltér e Fávero (2020) e Fávero (2009) investiga sobre a seguinte questão: os problemas enfrentados na docência que hoje causam o mal-estar docente podem encontrar nas políticas de formação pedagógica uma alternativa de enfrentamento? Trata-se de um estudo qualitativo, exploratório e bibliográfico de corte analítico (CONSALTÉR; FÁVERO, 2019), o qual se utiliza dos conceitos dos autores acima indicados para propor análises da verificação da existência de um mal-estar docente e possíveis estratégias de superação do mesmo frente a políticas de formação de professores. Sendo assim, com base no conceito

\section{Como referenciar este artigo:}

FÁVERO, A. A.; AGOSTINI, C. C.; RIGONI, L. M. Mal-estar docente e políticas de formação pedagógica. Revista Pedagógica, v. 23, p. 1-27, 2021. 
freudiano de "mal-estar", o presente texto tem por objetivo analisar a existência do malestar docente vivenciado pelos docentes no país, ante inclusive a realidade pandêmica atual e a necessidade de promover a adequação das políticas de formação pedagógica. A hipótese que perpassa o trabalho aqui apresentado é a de que os diversos problemas que o professor enfrenta no exercício da docência geram um mal-estar docente, sendo que um dos objetivos aqui inserem-se em apontar algumas discussões que implicam nesse diagnóstico e alternativas possíveis a partir do olhar sobre as políticas de formação pedagógica. Tal perspectiva se coloca como estratégia de resistência na atuação docente a forma como o modelo de educação contemporâneo vem sendo conduzido, o qual, por si só geral mal-estar docente e tem ganhado cada vez mais espaço nos sistemas educacionais como denunciam os estudos de Fávero; Tonieto; Consaltér (2020) Fávero; Pires; Consaltér (2020) e Fávero e Trevisol (2020).

Para dar conta dos objetivos propostos, o texto, após as considerações iniciais, encontra-se dividido em três tópicos. O primeiro, reconstrói o conceito de mal-estar apresentado por Freud (1997) na obra O mal-estar na civilização e na forma como tal conceito foi feita a apropriação a partir dos escritos do filósofo Sérgio Paulo Rouanet, o qual analisa o mal-estar da modernidade. O segundo tópico investiga o mal-estar docente a partir dos estudos do educador espanhol José Manuel Esteve. Por fim, no terceiro tópico são propostas algumas estratégias de superação do mal-estar docente por meio da ideia de reconstrução das políticas de formação pedagógica docente.

\section{MAL-ESTAR DA CIVILIZAÇÃO}

Há quase 90 anos era publicado em Viena um importante trabalho do pai da psicanálise. Inicialmente intitulado A infelicidade na cultura e depois rebatizado de $O$ malestar na cultura, foi traduzido no Brasil com o título de O mal-estar na civilização. Para Freud (1997), o "mal-estar" é o desconforto que o indivíduo sente devido aos sacrifícios que precisa fazer para viver em sociedade, podendo ou não ser diagnosticado por meio de patologias. A mensagem de Freud é clara: você ganha alguma coisa, mas, em contrapartida,

\section{Como referenciar este artigo:}

FÁVERO, A. A.; AGOSTINI, C. C.; RIGONI, L. M. Mal-estar docente e políticas de formação pedagógica. Revista Pedagógica, v. 23, p. 1-27, 2021. 
perde [...] alguma outra [...]. No plano erótico, por exemplo, o indivíduo abre mão do incesto ou da promiscuidade em troca da sexualidade exogâmica ou da monogamia e, com isso, é aceito como "normal” na sociedade. Essas renúncias são provenientes ou da autoridade externa ou dessa autoridade inserida no Superego. O "mal-estar" reside, portanto, no sentimento de culpa e frustração ocasionado por sacrifício da pulsão agressiva que o indivíduo faz para viver e ser aceito na sociedade. "O ressentimento contra a civilização", diz Sérgio Paulo Rouanet, "é uma consequência lógica desse mal-estar" (1993, p.96).

Na análise de Freud, "a vida, tal como a encontramos, é ordem demais para nós, proporciona-nos muitos sofrimentos, decepções e tarefas impossíveis" (1997, p.22). O sofrimento é uma ameaça constante em nossas vidas e, por isso, somos frequentemente ameaçados pelas enfermidades do nosso organismo, pelas ameaças externas e principalmente pelas decepções nos relacionamentos com os outros. Nosso corpo, como um organismo biológico, está condenado à decadência e à dissolução; o mundo externo pode se voltar contra nós a qualquer momento com forças de destruição esmagadoras e impiedosas (o que podemos fazer diante da implacável força de um tornado ou vendaval? Os relacionamentos com os outros, indispensáveis e constituidores de nosso ser no mundo, são constantemente passíveis de ameaça ou frustração.

Assim, "sob a pressão de todas essas possibilidades de sofrimento”, diz Freud, "não admiro que os homens se tenham acostumado a moderar suas reivindicações de felicidade" (1997, p.25). A tarefa de evitar o sofrimento acabou colocando em segundo plano a meta de obter prazer. Por isso, talvez, uma análise do modo como vivemos revele mais as estratégias utilizadas para evitar sofrimento do que o plano de metas para alcançar o princípio de prazer. Certamente um dos propósitos mais intensos do ser humano é a obtenção da felicidade. "Todos querem ser felizes e assim permanecer", diz Freud (1997, p.23). No entanto, esse desejo não está inscrito no plano da “criação". Aquilo que é chamado de felicidade, nas palavras de Freud (1997, p.24), "provém da satisfação (de preferência, repentina) de necessidades represadas em alto grau, sendo, por sua natureza, possível apenas como uma manifestação episódica." O prolongamento da felicidade não

\section{Como referenciar este artigo:}

FÁVERO, A. A.; AGOSTINI, C. C.; RIGONI, L. M. Mal-estar docente e políticas de formação pedagógica. Revista Pedagógica, v. 23, p. 1-27, 2021. 
traz sentimento majorado e sim sentimento de contentamento muito pequeno, já que o prazer é feito de um contraste (FREUD, 1997).

A advertência de Freud escancara a condição humana. Apesar de todos os apelos ingênuos que a sociedade de hoje banaliza, a felicidade é uma excepcionalidade fortuita, e a tentativa de evitar o sofrimento é uma constante luta que se traduz nos motivos da vida. A fim de suportar os sofrimentos e as decepções que o viver nos proporciona, utilizamos permanentemente estratégias para enfrentar a vida árdua. Freud (1997, p.22-23) indica três medidas paliativas para enfrentar a vida árdua: a) derivativos poderosos, que nos fazem extrair luz de nossa desgraça - é quando as situações difíceis são enfrentadas com atividades construtivas de superação (as atividades científicas são um derivativo desse tipo de estratégia); b) satisfações substitutivas: são as ilusões ou fantasias oferecidas pela arte, que contrastam com a realidade (tal paliativo é possível, diz Freud, graças ao papel que a fantasia assumiu na vida mental); c) substâncias tóxicas: é a utilização de substâncias que influenciam nosso corpo e alteram a sua química (tais substâncias fazem com que nos tornemos insensíveis à vida árdua). Certamente todos os paliativos apontados por Freud são indicadores potentes para analisar o mal-estar docente que se observa na atualidade, o qual aqui questionamos.

Portanto, os conceitos de Freud são fundamentais para compreender o surgimento do mal-estar como um mal da modernidade, do tempo em que vivemos hoje, inclusive o fazendo indicações de medidas que podem auxiliar no desenrolar de desse sofrimento. Dentre elas encontra-se as atividades científicas, as artes e outras menos saudáveis, as quais podemos verificar presentes, em maior ou menor grau na sociedade e que atingem vertiginosamente a educação. Nesse sentido, fundamental acompanharmos algumas reflexões sobre o desdobramento desse mal-estar da civilização, naquilo que Sérgio Paulo Rouanet (1993) chama de "mal-estar da modernidade".

É lugar-comum nos meios acadêmicos, principalmente nos espaços ocupados pela educação e filosofia, dizer que "a modernidade está em crise". Não resta dúvidas de que tal crise exista e provoque um certo desconforto, e de que haja também a despedida de utopias que, por certo tempo, foram responsáveis por alimentar certos projetos

\section{Como referenciar este artigo:}

FÁVERO, A. A.; AGOSTINI, C. C.; RIGONI, L. M. Mal-estar docente e políticas de formação pedagógica. Revista Pedagógica, v. 23, p. 1-27, 2021. 
educacionais e de sociedade. No entanto, é importante e fundamental que se compreendam os alcances dessa crise e o significado desse diagnóstico. "O que está em crise", diz Sérgio Paulo Rouanet em seu livro Mal-estar da modernidade, "é o projeto moderno de civilização, elaborado pela llustração europeia a partir dos motivos da cultura judeo-clássica-cristã e aprofundado nos dois séculos subsequentes por movimentos como o liberal-capitalismo e o socialismo" (1993, p.9). Trata-se de um projeto civilizatório que trazia como ingredientes principais os conceitos de universalidade, individualidade e autonomia, com objetivo de atingir todos os seres humanos.

Assim, na avaliação de Rouanet (1993, p.9-10), “esse projeto civilizatório está fazendo água por todas as juntas" : o universalismo está sendo sabotado pela proliferação dos particularismos; a individualidade submerge no anonimato do conformismo e da sociedade de consumo; e, por fim, a autonomia intelectual, baseada na visão secular do mundo, cede lugar ao "reencantamento do mundo", a autonomia política é negada por ditaduras ou transformada em espetáculo eleitoral e a autonomia econômica é uma mentira sádica para os três terços da população mundial, condenada a viver nas condições de pobreza absoluta.

O que fazer diante desse "vácuo civilizatório", chamado intencionalmente por Rouanet de "barbárie", uma vez que o bárbaro é assim denominado porque vive fora da civilização? De que maneira essa "barbárie influencia o mal-estar docente constatado no cenário educacional? Que alternativas se apresentam viáveis para enfrentar a letargia proveniente da crise da modernidade? O próprio Rouanet (1993, p.12) apresenta três alternativas: a) podemos ignorar o estado de crise e simplesmente desconsiderar a existência da "barbárie"; b) podemos partir para um modelo civilizatório antimoderno, advogando uma espécie de antítese de tudo aquilo que representa a modernidade; e, por fim, c) podemos repensar a modernidade, em busca de uma alternativa neomoderna.

Não faltarão partidários para defender a primeira alternativa, diz Rouanet, pois hoje em dia a barbárie não assusta mais. Mas quem são, então, esses novos bárbaros? Os bárbaros de hoje não vestem mais peles de ursos, nem impunham lanças ou comem javalis; no entanto, têm como característica principal uma atitude contracultura e o desprezo pela

\section{Como referenciar este artigo:}

FÁVERO, A. A.; AGOSTINI, C. C.; RIGONI, L. M. Mal-estar docente e políticas de formação pedagógica. Revista Pedagógica, v. 23, p. 1-27, 2021. 
razão. "Os verdadeiros bárbaros", diz Rouanet, "retalham a lugoslávia em nome da nação e assassinam milhares de homens, mulheres e crianças. Em defesa do povo matam de fome na Somália uma população inteira. Para maior glória do Islã condenam à morte um escritor sacrílego" (1993, p.12).

Defender um projeto antimoderno de civilização implica, como o próprio nome anuncia, realizar uma antítese de tudo aquilo que o projeto moderno propõe: “o particularismo em vez do universalismo, o holismo em vez da individualidade, a religião em vez do desencantamento, a autoridade em vez da liberdade, e a estratificação em vez da mobilidade socioeconômica" (ROUANET, 1993, p.13). De uma certa forma, é possível afirmar que tal projeto já está se desenhando nas proposições dos políticos conservadores, nos fundamentalistas religiosos e nas posições radicais dos pós-modernos, embora pareça que esses grupos pretendam desenhar esse cenário e seu discurso sob o abrigo dos princípios democráticos, liberais e laicos.

A terceira alternativa - uma civilização neomoderna que seja capaz de manter o que existe de positivo na modernidade, corrigindo suas patologias - consiste, grosso modo, numa clara tentativa de concretizar a civilização iluminista ${ }^{4}$. A ideia iluminista apostou no projeto de que todos os homens e mulheres, independentemente de nação, raça, etnia ou religião, poderiam alcançar a autonomia intelectual, ou seja, a emergência do homem capaz de fazer uso da sua própria razão, como Kant expressa muito bem no famoso texto Resposta à pergunta: que é “esclarecimento"? (Aufklärung). "Esclarecimento”, diz Kant, “é a saída do homem de sua menoridade, da qual ele próprio é culpado. [...] Sapere aude! Tem coragem de fazer uso de teu próprio entendimento, tal é o lema do esclarecimento" (1985, p.100).

4 Considerado como "a destilação teórica da corrente de idéias que floresceu no século XVIII em torno dos filósofos enciclopedistas como Voltaire e Diderot, e de "herdeiros" dessa corrente, como o liberalismo e o socialismo, que, incorporando de modo seletivo certas categorias da llustração, levaram adiante a cruzada ilustrada pela emancipação do homem" (ROUANET, 1993, p.13-14).

\section{Como referenciar este artigo:}

FÁVERO, A. A.; AGOSTINI, C. C.; RIGONI, L. M. Mal-estar docente e políticas de formação pedagógica. Revista Pedagógica, v. 23, p. 1-27, 2021. 
No entanto, esse projeto tornou-se, no final do século XIX e no século XX, motivo de mal-estar. Trata-se de um ressentimento contra esse modelo de civilização, contra o Iluminismo, contra o projeto que visava, na expressão de Rouanet (1993, p.97), à "autoemancipação de uma humanidade razoável" consubstanciada no racionalismo, no individualismo e no universalismo. O racionalismo nesse projeto implicava o desencantamento e a crítica da religião, da tradição, dos valores herdados. O individualismo significava o rompimento com as antigas cosmologias comunitárias (nas quais o homem só valia como parte do coletivo), e a emergência de uma nova ética e uma nova política, em que o homem valeria por si mesmo. A concepção de universalismo estava subjacente a dissolução dos particularismos locais, postulando a imagem de uma natureza humana universal.

Assim, o mal-estar da modernidade, grosso modo, se apresenta como uma contestação a todos os elementos que formaram a agenda do projeto iluminista: o racionalismo cede lugar ao irracionalismo, que se difunde nas atitudes e comportamentos sociais; o indivíduo é solapado tanto pelo conformismo inerente à moderna sociedade de massas como pelas tentativas de reagir à massificação; por fim, o universalismo sucumbe ao particularismo, que se consubstancia nas diversas formas de racismos, nacionalismos, regionalismos e tribalismos. Nesse contexto antimoderno de mal-estar, diz Roaunet, "a razão pesa como um jugo, e os homens se libertam dela lendo Paulo Coelho" (1993, p.99).

E dentro desse constructo, que implicações esse mal-estar tem para o campo educacional? Como se situa a escola, de modo geral, e os educadores, de modo específico, nesse processo de crise da modernidade? Que consequências a crise da modernidade está trazendo para o campo das políticas educacionais de formação de educadores? De que maneira pode ser enfrentado o mal-estar docente que se instaurou no seio da atual crise educacional?

\section{MAL-ESTAR DOCENTE}

Como referenciar este artigo:

FÁVERO, A. A.; AGOSTINI, C. C.; RIGONI, L. M. Mal-estar docente e políticas de formação pedagógica. Revista Pedagógica, v. 23, p. 1-27, 2021. 
O mal-estar docente, na perspectiva apresentada, com o resgate de fundamentos de sua origem como foi entabulado acima, não é uma situação nova e parece permear a profissão a algum tempo. Para quem investiga sobre o tema e vem acompanhando a situação no decorrer dos anos, é comum observar pesquisas que apontam os dilemas e problemas enfrentados pelos docentes nas últimas décadas. Como exemplo, podemos citar uma reportagem expressiva pelo seu destaque de capa, da Revista Educação, publicada no ano de 2007, que indicou que 50\% dos professores brasileiros apresentavam sintomas de estresse ou depressão. "O professor está doente", afirmou a reportagem5.

Feita por Fabiano Curi (2007), a reportagem, na sequência, chamou a atenção para as pesquisas sobre o estado de saúde do professor. As péssimas condições de trabalho, o excesso de tarefas, a pressão por requalificação profissional e a falta de apoio institucional, entre outros problemas enfrentados no dia-a-dia, fazem com que os professores se tornem um dos grupos mais sujeitos a terem transtornos psíquicos. Nesse sentido, como é afirmando na reportagem o chamado sistema escolar, acaba por transferiria ao docente a responsabilidade para atender as diversas fragilidades existentes no contexto escolar em que se encontram que, por sua vez, passa a estabelecer uma série de mecanismo que atuam de forma rígida e redundantes para proferir uma avaliação profissional (CURI, 2007). O aparecimento da síndrome de burnout $^{6}$ é apenas uma das poucas manifestações do estado preocupante de saúde dos professores. Pesquisas realizadas pela Universidade de Brasília no final da década de 1990 também mostraram que 48\% dos professores apresentam algum sintoma da síndrome. Resultado semelhante foi constatado numa pesquisa feita no 2003 pelo Sindicato dos professores do Ensino Oficial do Estado de São Paulo (FÁVERO, 2015).

5 Como destaque, referiu que "excesso de trabalho, indisciplina em sala de aula, salário baixo, pressão da direção, violência, demandas de pais de alunos, bombardeio de informações, desgaste físico e, principalmente, a falta de reconhecimento de sua atividade são algumas das causas de estresse, ansiedade e depressão que vêm acometendo os docentes brasileiros" (CURI, 2007, p.30).

6 A síndrome de burnout foi o nome dado nos anos de 1970 para a síndrome do esgotamento profissional. 0 nome vem da expressão em inglês to burn out, ou seja, queimar completamente, consumir-se.

\section{Como referenciar este artigo:}

FÁVERO, A. A.; AGOSTINI, C. C.; RIGONI, L. M. Mal-estar docente e políticas de formação pedagógica. Revista Pedagógica, v. 23, p. 1-27, 2021. 
Em relação a esse aspecto, pode-se referir que, dá-se ao professor autonomia, esta que é associada à satisfação, envolvimento, desempenho, comprometimento e motivação. Por outro lado, negativamente, é associada a sintomas de estresse emocional, de desmotivação e de estresse físico, então ocorre um esforço crucial na realização da função. Isso pode ocorrer nos profissionais altamente motivados, que acabam se excedendo e não suportando a rotina de sobrecarga do trabalho. Nesse sentido, Sacristán considera que "grande parte dos problemas e temas educativos conduz a uma implicação dos professores, exigindo-lhes determinadas atuações, desenhando ou projetando sobre a sua figura uma série de aspirações" (SACRISTÁN, 1999, p.64), e tais atuações são justificadas como condição para melhoria e implemento do processo educativo, sem que essa relação esteja efetivamente comprovada.

É preciso de incentivo à superação das situações que desequilibram e fazem pensar em desistir da luta diária. Com as mudanças ocorridas, a profissão docente também foi afetada pela síndrome, que afeta a sociedade num modo geral, denominada de Burnout, expressão inglesa que significa aquilo que deixou de funcionar por exaustão. Destacam-se, ainda, outras definições, a partir dos estudos realizados por Codo (2006), o qual, em seus estudos, analisou diversos autores os quais definiram a síndrome. De forma geral, as concepções perpassam na identificação de um trabalho exaustivo, monótono, entediante, o qual desconsidera as próprias necessidades, à aquela que sugerem tensão psicológica advinda de contato direto com outras pessoas, clientes, com comprometimento não correspondido e sentimento de frustração decorrente (CODO, 2006).

O diagnóstico da doença de Burnout só pode ser realizado por um médico ou psicoterapeuta e o tratamento poderá seguir algumas regras terapêuticas, que consistem no acompanhamento de um psicoterapeuta e o uso de bons medicamentos, bem como de mudanças no estilo de vida como: lazer, exercícios físicos regulares, alimentação balanceada, diminuição no consumo de álcool e outras drogas.

Dentre as atividades mais desgastante e desafiadoras da atualidade, a de ser professor se sobressai. Segundo corrobora Kant (2004), as artes mais difíceis da humanidade são a arte de governar e a arte de educar. Presumindo, mesmo não

\section{Como referenciar este artigo:}

FÁVERO, A. A.; AGOSTINI, C. C.; RIGONI, L. M. Mal-estar docente e políticas de formação pedagógica. Revista Pedagógica, v. 23, p. 1-27, 2021. 
conhecendo o trabalho docente, o autor já declarava o quão difícil é se envolver com a educação. Sabendo da grande importância que tem a educação, os profissionais acabam sofrendo por terem consciência do objetivo e não conseguirem chegar até ele, devido a diversas circunstâncias que se criam em sua trajetória. E isso é corroborado pelo modelo de educação que se propõe na atualidade, pautado pelo neoliberalismo e o empreendedorismo de si, no qual o indivíduo torna-se responsável pelo seu sucesso e fracasso, sendo que isso perpassa de forma profunda a atuação profissional (FÁVERO; TONIETO; CONSALTÉR (2020), FÁVERO; PIRES; CONSALTÉR (2020) E FÁVERO E TREVISOL (2020). O docente também é inserido nessa lógica, já que o sucesso da aprendizagem do aluno passa pela sua excelência enquanto profissional, sem que os demais fatores sejam levados em consideração. E isso contribui consideravelmente para o mal-estar, ante o sentimento de impotência e desespero gerado pela imobilidade frente a diversos fatores geradores do chamado insucesso educacional.

Não é preciso ir muito além para verificar a presença do sofrimento identificado por Freud, suas fórmulas para superar, com uso de substâncias não saudáveis, por exemplo, e irracionalismo de Rouanet podem estar presentes no mal-estar docente contemporâneo. A síndrome de burnout, as implicações do autoempreendedorismo da educação neoliberal e a carga de responsabilidade sobre o docente, responsável por boa parte do sucesso educacional geral um sofrimento psicossomático, o qual prejudicam a vida e eu exercício da profissão.

Uma outra reportagem, organizada por Paola Gentile e publicada na Revista Nova Escola, no ano de 2007, revelou que, segundo pesquisas, em uma amostra de 500 professores da rede pública 63\% deles relatam viver num nível significativo de estresse, 48\% sentem falta de mais segurança contra a violência, 54\% estão descontentes com os benefícios e $47 \%$ com o salário, e apenas $21 \%$ se dizem satisfeitos com a profissão (GENTILE, 2007).

No Brasil de 2020, frente o enfrentamento da Pandemia de Covid-2019 que assola o planeta, a situação docente não se mostra diferente, tampouco motivadora. Com a declaração de necessidade de isolamento social como medida de combate ao vírus, as

\section{Como referenciar este artigo:}

FÁVERO, A. A.; AGOSTINI, C. C.; RIGONI, L. M. Mal-estar docente e políticas de formação pedagógica. Revista Pedagógica, v. 23, p. 1-27, 2021. 
instituições escolares foram fechadas e as aulas substituídas pelo ensino remoto, on-line. No entanto, para os docentes, além da necessidade de alteração das aulas para o modelo on-line e remoto, surgiu o fantasma da demissão, do corte de salário, do acumulo de trabalho, além da responsabilidade de manter os alunos participantes e engajados. Há relatos de sofrimento psíquico docente, os quais encontra-se absortos na necessidade de dar conta das suas atribuições docentes específicas, conjugadas com novas responsabilidades acumuladas es pressões externas acaloradas, sob mundo em pleno colapso. (ALVES, 2020)

Exemplificando a situação, a reportagem do El País Brasil (DOMINCINI, 2020), de setembro de 2020, relata a situação descrita como "cruel" vivenciada pelos docentes do ensino superior no país, durante a pandemia. Segundo a reportagem, professores de instituições privadas, estão tendo de atuar com carga horária reduzida ao extremo (ex.de 21 horas para 3 horas semanais), com salas de aula virtuais de 300 alunos e ainda demissões por "pop ups" nas telas de trabalho dos sistemas de aprendizagem virtual nos quais estão vinculados. Sob o risco de demissão ou de não conseguir pagar as contas pela redução extrema dos vencimentos, os professores relatam sentimentos de angústia, ansiedade, e até mesmo o extremo, de pensamentos suicidas. Diversas plataformas de apoio psicológico aos docentes têm surgido nesse período, como relata a reportagem, e seus organizadores revelam aumento expressivo de relatos de docentes com problemas psicológicos. O responsável pela Plataforma citada na reportagem, criada pelo coletivo Rede de Educadores do Ensino Superior em Luta relata que, poucas horas após o lançamento, houve 300 pedidos de atendimentos, o que demonstra a situação precária e preocupante enfrentada pelos docentes (DOMINCINI, 2020).

Mas não precisaríamos recorrer a estatísticas nem fazer grandes deduções lógicas, ou muito menos intensas pesquisas nas mídias atuais, para constatar que o professor vive hoje aquilo que o educador espanhol José Manuel Esteve cama de mal-estar docente. “A expressão 'mal-estar' docente", diz ele no prólogo à terceira edição espanhola, "é intencionalmente ambígua. [...] A dor é algo determinado e que podemos localizar. A doença tem sintomas manifestos. Quando usamos o termo 'mal-estar' sabemos que algo

\section{Como referenciar este artigo:}

FÁVERO, A. A.; AGOSTINI, C. C.; RIGONI, L. M. Mal-estar docente e políticas de formação pedagógica. Revista Pedagógica, v. 23, p. 1-27, 2021. 
não vai bem, mas não somos capazes de definir o que não funciona e por quê" (ESTEVE, 1999, p.12). Penso que a escolha feita por Esteve é oportuna e provocativa para pensarmos a atual situação em que se encontra o professor no contexto das profundas crises que enfrenta como profissional da educação. Trata-se de um sentimento, um sofrimento aos moldes freudianos, um mal-estar generalizado dos tempos contemporâneos em que vivemos, causando dores físicas e emocionais nos docentes. O sofrimento torna-se uma premissa presente na atuação do professor, sendo que a busca pelo prazer e o amor a educação parece sucumbir.

Sendo assim, o mal-estar docente pode compreender a insatisfação dos profissionais diante diversas situações vivenciadas ao longo de sua carreira profissional, estas, gerando alto grau de estresse, desinteresse e até abandono da profissão, podendo resultar em depressão. Perdendo a autoestima, desanimados e insatisfeitos “[...] muitos têm vergonha de declarar a profissão ou de falar do seu trabalho. Fogem ao ideal da realização e sucesso, exigido pela modernidade" (OLIVEIRA, 2006, p.12).

Incumbe-se situações difíceis em relação aos educandos, nas quais os professores não são capazes de solucionar, pois não depende apenas deles. Na busca por soluções, muitas vezes sozinhos, não conseguem alcançar os objetivos, gerando a ideia de incapacidade. Precisam, então, manter o estado psicológico preparado, pois, "os professores são criticados por não garantirem na escola aquilo que a sociedade não consegue fornecer fora dela" (NÓVOA, 2002, p.57). O professor sozinho não consegue solucionar problemas impostos pela sociedade e nisto reside o sofrimento já indicado por Freud (1997), gerando ameaça ou frustração, como um projeto social de mal-estar, descrito por Rouanet (1993).

O mal-estar é fruto de um conjunto de contradições que se avolumam no cenário social em que o professor está inserido. Vivemos numa sociedade em que as exigências econômicas e sociais massificaram a escola. Como nos diz Luiza Cortezã, "cada vez é menos possível ignorar os custos de se ter tentado resolver os problemas surgidos com a emergência da escola de massas através da massificação do ensino" (2002, p.15). No entanto, essa mesma sociedade exige que se mantenha um nível de excelência numa

\section{Como referenciar este artigo:}

FÁVERO, A. A.; AGOSTINI, C. C.; RIGONI, L. M. Mal-estar docente e políticas de formação pedagógica. Revista Pedagógica, v. 23, p. 1-27, 2021. 
escola de massas. "O que é insustentável”, diz Esteve, "é manter as exigências de um sistema de elite, em um sistema de massa que não pode oferecer em troca nem uma qualidade digna de ensino, por falta de professores preparados, nem esperança de um trabalho qualificado ao término dos estudos" (1999, p.20). Dentro desse contexto, muitos fatores poderiam ser apontados como indicadores do mal-estar docente. No momento, procuramos nos deter e analisar alguns dos que foram considerados por Esteve em seu livro já mencionado. Um primeiro fator é a "modificação no papel do professor e dos agentes tradicionais de socialização".

As rápidas transformações sociais, a versatilidade das informações, as modificações do mundo do trabalho e da estrutura familiar, o deslocamento de certos setores produtivos etc., fizeram que com aumentassem a responsabilidade e as exigências dos educadores. No entanto, essas transformações não foram acompanhadas pelas necessárias mudanças no processo da formação profissional dos educadores, provocando uma crise tanto da instituição escolar [...]. Assim vive-se a fase de desencanto do magistério, marcada pela subvalorização da formação de professores. Somado a essa situação, encontramos, também, o "aparecimento de novos agentes de socialização (meios de comunicação e consumo cultural de massas etc.), que se convertem em fontes paralelas de transmissão de informação e cultura" (ESTEVE, 1999, p.29).

O professor, que 30 anos atrás era considerado exclusiva fonte de informação e transmissão de saber, encontra-se no momento desbancado pela oferta de ferramentas midiáticas capazes de oportunizar aos alunos o acesso para verificar qualquer uma das informações que venha a apresentar. "Muitos professores souberam integrar e utilizar com harmonia as vantagens que oferecem esses novos agentes", diz Esteve, "enquanto muitos outros se obstinam em manter seu papel tradicional, ignorando a enorme força de penetração e o interessante potencial educativo que os novos canais de informação poderiam colocar a serviço" (1999, p.30). Exemplificamos ainda que, em tempos de pandemia, a situação parece ganhar nova roupagem, ao passo que o papel do professor é questionado não só na possível insuficiência de sua formação ou por se apresentar frágil frente a essa realidade digital, mas na viabilização de sua substituição por uma máquina

\section{Como referenciar este artigo:}

FÁVERO, A. A.; AGOSTINI, C. C.; RIGONI, L. M. Mal-estar docente e políticas de formação pedagógica. Revista Pedagógica, v. 23, p. 1-27, 2021. 
(ALVES, 2020). Todas essas situações, são motivos evidentes do mal-estar docente contemporâneo.

Um segundo fator que provoca o mal-estar situa-se "na contestação e nas contradições da função docente". As diversas transformações apontadas anteriormente são responsáveis por não existir o amparo do consenso social, tão fortemente presente em outras épocas. Durante muito tempo o que a escola determinava ou afirmava era endossado e confirmado pelos pais; hoje, diferentemente, "qualquer atitude do professor pode ser contestada, e haverá grupos e forças sociais dispostos a apoiar a contestação ao professor. Qualquer valor que se defenda em classe pode ser rebatido, não somente na perspectiva individual de um aluno, mas com o apoio de diferentes correntes de opinião que têm suas origens nos meios de comunicação de massa” (ESTEVE, 1999, p.31).

As alterações no exercício docente advindas do contexto social, pode ser apontado como um outro elemento do mal-estar docente. Na atualidade, diz Esteve, "muitos professores se queixam que os pais não só despreocupam-se de difundir em seus filhos valores mínimos, convictos de que essa é uma obrigação que só cabe aos professores, como também estão de antemão dispostos a culpar os professores" (1999, p.33). Assim, a valorização do trabalho docente só é reconhecida no sentido negativo, ou seja, se há uma dedicação exaustiva por parte do professor, dificilmente alguém reconhece; no entanto, se há um fracasso por diversas razões já mencionadas anteriormente no presente texto, imediatamente o fracasso é personalizado no professor.

Hoje o docente é chamado a instigar e fomentar o interesse dos alunos, na participação das atividades, mesmo em meio on-line, e responsabilizado caso isso não ocorra. No entanto, torna-se essa uma tarefa inglória, pelo fato que o mesmo concorre com situações que perpassam desde a dificuldade do aluno no acesso à aula virtual, até mesmo a concorrência com mídias de diversão (ex: redes sociais), o que influenciam na aprendizagem, rendimento escolar e implicam diretamente no sucesso ou fracasso dos alunos em seus estudos. Há nesse sentido uma ideia generalizada de que, se os alunos estão indo bem na escola, os pais pensam que seus filhos são bons alunos, inteligentes,

\section{Como referenciar este artigo:}

FÁVERO, A. A.; AGOSTINI, C. C.; RIGONI, L. M. Mal-estar docente e políticas de formação pedagógica. Revista Pedagógica, v. 23, p. 1-27, 2021. 
dedicados; mas, se as coisas vão mal, pensam que os professores e a escola não estão cumprindo com seu papel.

Essa modificação do apoio do contexto social está também ligada à modificação do status social do professor. Até um pouco mais dos meados do século XX se atribuía ao educador um status social e cultural elevado. Estimava-se no educador seu saber, sua vocação, sua cultura, sua abnegação. Contrariamente a esse perfil, o status social hoje é medido pela renda salarial. A diminuição do poder aquisitivo do salário do professor fez com que este também fosse perdendo seu status social. Muitas pessoas veem na opção de alguém por ser professor um reflexo de sua incapacidade de fazer "algo melhor" e que dê mais dinheiro. É por isso que Esteve indica a modificação do apoio do contexto social - e o nível salarial não deixa de ser a manifestação dessa modificação - como um importante fator do mal-estar docente.

O avanço contínuo do conhecimento também pode ser caracterizado como fator que provoca o mal-estar docente. Não resta dúvida de que a multiplicação dos conhecimentos científicos causada pelo avanço das ciências, a proliferação das informações possibilitadas pelas modernas tecnologias e o aumento da escolarização resultante dos avanços sociais e políticos e das necessidades econômicas oportunizaram um incrível avanço do conhecimento. Todas essas mudanças foram importantes e causaram um impacto positivo na democratização do saber. No entanto, a contrapartida desse avanço acarretou um mal-estar que se deve, em grande parte, à insegurança quanto o quê ensinar e a como garantir uma atualização do saber eficaz. "Quem poderia estar seguro, no momento atual, de ensinar os últimos conhecimentos em sua área?”, pergunta Esteve. E continua: “Quem poderia estar seguro de que o que ensina não poderia ser substituído por outros conhecimentos mais úteis a esses alunos, a quem estamos tentando preparar para uma sociedade que ainda não existe?" (1999, p.37).

A imagem do professor frente a imprensa e outros meios de comunicação social também é indicado por Esteve como fator do mal-estar docente. Ao selecionar recortes da imprensa (jornais, revistas) e acompanhar filmes e séries televisivas centradas na figura do professor, Esteve constatou que tais veículos apresentam uma visão idílica do educador, a

\section{Como referenciar este artigo:}

FÁVERO, A. A.; AGOSTINI, C. C.; RIGONI, L. M. Mal-estar docente e políticas de formação pedagógica. Revista Pedagógica, v. 23, p. 1-27, 2021. 
qual é, contudo, completamente contrária à imagem que o professor faz de si mesmo. Nos filmes, por exemplo, a maior parte do tempo não é dedicada para tratar do espaço da sala de aula, e sim das atividades relacionais do professor, geralmente fora da sala de aula. “Com esse enfoque idílico, o professor”, diz Esteve, "mais do que como educador, aparece como amigo e conselheiro. É a imagem atraente da profissão docente com que os professores tendem a identificar-se; mas que [...] está muito distante da realidade dos centros educativos" (1999, p.41).

Essa imagem idílica do professor apresentada pelos meios de comunicação produz dois polos na evolução do conceito profissional dos educadores. Num primeiro momento, na formação inicial dos professores, tende a estimular o estereótipo ideal, que representaria o lado positivo da imagem do professor. No entanto, o "choque com a realidade" que o neoprofessor (autoempreendedor, responsável pelo seu sucesso e pelo sucesso da educação) precisa enfrentar acaba por destruir essa imagem idílica. A prática docente nas escolas faz com que essa imagem ideal entre em crise em cinco a seis anos de docência. "Assim”, diz Esteve, “o professor vai constatar que a realidade do magistério não corresponde aos ideais que aprendeu durante seu período de formação, e com os quais se compara ele mesmo e o compara boa parte da sociedade" (1999, p.44). Tudo isso contribui para ampliar ainda mais o mal-estar docente.

Haveria vários outros fatores que poderiam ser mencionados na caracterização do mal-estar docente. Poderíamos falar de fatores referentes ao contexto no qual a docência é exercida, como a falta de recursos materiais e as condições de trabalho limitadoras da atuação docente, o aumento da violência nas instituições escolares e o esgotamento docente perante o acúmulo de exigências que recaem sobre o professor, como tecemos breves comentários no início dessa sessão. Todos esses fatores são efetivamente influenciadores para ampliar o mal-estar docente que devido a sua amplitude, podem gerar inúmeras, robustas e profícuas discussões. No entanto, feito o diagnóstico cabível a nossos objetivos, torna-se necessário indicar ainda algumas alternativas para o enfrentamento do mal-estar docente.

\section{Como referenciar este artigo:}

FÁVERO, A. A.; AGOSTINI, C. C.; RIGONI, L. M. Mal-estar docente e políticas de formação pedagógica. Revista Pedagógica, v. 23, p. 1-27, 2021. 
Revista do Programa de Pós-Graduação em Educação da Unochapecó ISSN 1984-1566 (on-line) ISSN 1415-8175 (impressa)

\section{POLÍTICAS DE FORMAÇÃO PEDAGÓGICA COMO POSSIBILIDADE DE ENFRENTAMENTO O MAL-ESTAR DOCENTE}

A busca de um ideal de formação abrangente do ser humano se confunde com a história do ocidente. Ao definir o lugar dos gregos na história da educação, Werner Jaeger (1989), em sua Paidéia, inicia dizendo que "todo povo que atinge um certo grau de desenvolvimento sente-se naturalmente inclinado à prática da educação. Ela é o princípio por meio do qual a comunidade humana conserva e transmite a sua peculiaridade física e espiritual” (1989, p.3). Com isso, nossa intenção é defender a tese de que uma das formas de enfrentar o mal-estar docente, descrito nos tópicos anteriores, está em investir em políticas de formação pedagógica. Como bem ressaltam Fávero e Tonieto (2010, p.19) a docente necessita tornar-se "problemática de investigação" e com isso "compreender a crise educacional [...] para que seja possível novos modos de pensar e agir frente aos problemas educacionais".

Mas o que se entende por políticas de formação pedagógica? Como elas se situam no atual contexto? Por que é tão difícil a sua efetivação? Que aspectos precisam ser considerados quando falamos de formação pedagógica? Ainda faz sentido tratarmos desse assunto numa sociedade pós-industrial, marcada pelo acirramento da competição desregrada que acentua o individualismo possessivo?7 Como abordar a formação pedagógica diante do incremento gigantesco das novas tecnologias presentes tanto no âmbito educacional quanto na vida cotidiana [...]? De que modo pensar a formação como pertencente à essência da comunidade se nosso contexto indica um ethos marcadamente relativista, individualista e narcisista? É possível um projeto coletivo de formação pedagógica diante de um cenário em que ocorre a precarização da educação formal, reduzida ao imediatismo, à massificação, à sobreposição da lógica do sentido priva do sobre o público, da lógica neoliberal capitalista impregnada na educação e nas suas políticas

7 Algumas dessas questões foram abordadas no texto "A formação cultural como exigência para a formação docente: aproximações a partir das concepções filosófico-educativas de Adorno" (FÁVERO; CENCl; DALBOSCO, 2008).

\section{Como referenciar este artigo:}

FÁVERO, A. A.; AGOSTINI, C. C.; RIGONI, L. M. Mal-estar docente e políticas de formação pedagógica. Revista Pedagógica, v. 23, p. 1-27, 2021. 
educacionais e à abdicação do saber e destituição de certas funções próprias da escola? São questões certamente importantes e que necessitam de um espaço mais amplo do que o previsto neste texto.

Ao indicar as estratégias para evitar o mal-estar docente, José Manuel Esteve adverte que, "uma vez estudada a presença do mal-estar docente e os mecanismos pelos quais ele é produzido, estamos em condições de articular soluções coerentes que evitem o aumento, constatado nos últimos anos, das repercussões negativas do exercício da docência sobre a personalidade dos professores" (1999, p.117). Para tanto, ele distingue duas abordagens diferentes na apresentação de possíveis soluções: de um lado, uma abordagem preventiva destinada à formação inicial dos professores; do outro, uma abordagem que articula estruturas de ajuda destinada ao professorado em exercício (formação continuada). Nesse sentido, com relação à abordagem preventiva, Esteve indica três grandes estratégias de atuação no processo de formação: a) seleção inicial do professorado; b) substituição dos enfoques normativos por enfoques descritivos; c) adequação dos conteúdos da formação inicial à realidade prática do magistério.

Em relação à estratégia da seleção inicial do professorado, Esteve é favorável à ideia de que o processo seletivo de acesso à profissão docente deveria estar baseado em critérios de personalidade, analisando as condições psíquicas, e não somente de qualificação intelectual. Para defender tal posição, o autor ancora-se em estudos realizados pela Unesco em 1959, os quais foram posteriormente ampliados por outros pesquisadores. Tais estudos mostram que tal estratégia evitaria "o acesso à profissão docente de pessoas desequilibradas, cuja fragilidade os expõe tanto a um fracasso certo na relação educativa quanto à possibilidade de multiplicar seus problemas, produzindo efeitos psicológicos negativos sobre os alunos" (1999, p.119). Esta posição vai justamente na contramão das práticas seletivas para o ingresso dos alunos nos cursos de licenciatura. Cada vez mais os alunos que buscam tais cursos revelam-se despreparados, não psicologicamente, mas também intelectualmente. As condições precárias de oferta, conjugados com a dura realidade que os alunos enfrentam para realizar o curso, acabam resultando numa formação precária dos futuros educadores.

\section{Como referenciar este artigo:}

FÁVERO, A. A.; AGOSTINI, C. C.; RIGONI, L. M. Mal-estar docente e políticas de formação pedagógica. Revista Pedagógica, v. 23, p. 1-27, 2021. 
No que diz respeito à segunda estratégia, Esteve adverte que "os enfoques normativos têm orientado a formação inicial do professor praticamente desde a aparição do conceito de formação inicial" (1999, p.123). Ele entende por enfoque normativo os programas de formação do professorado orientados por um modelo de professor "eficaz" ou "bom" que perdura até os nossos dias e que, segundo sua avaliação, "tem graves efeitos negativos sobre a personalidade dos professores, constituindo uma importante fonte de ansiedade em sua atividade profissional" (1999, p.125).

O professor formado segundo esse enfoque normativo tende a culpar-se pelo insucesso do trabalho pedagógico tão logo aparecem os primeiros conflitos. Por não se encaixar no modelo de "professor ideal" com o qual havia se identificado durante a formação inicial, pode entrar num período de crise de identidade profissional, o que o leva a abandonar o magistério. Outros tentam manter a "máscara" do modelo normativo que interiorizaram durante o processo de formação, porém vivem a angústia de ser, a qualquer momento, desmascarados pelo fracasso que sua própria prática pode revelar. "Em compensação", diz Esteve, "se se utilizam enfoques descritivos, considerando que o êxito no magistério depende de uma atuação correta do professor que responda ao conjunto de condições que influem na interação professor-aluno, quando os professores iniciantes deparam com suas primeiras limitações e fracassos, questionam sua atuação, mas não começam, ao menos não desde o princípio, a questionarem-se a si mesmos" (grifos do autor, 1999, p.126-7). Utilizar modelos descritivos faz com que o professor, ao perceber um certo fracasso, passe a ter uma atitude investigativa a fim de corrigir sua atuação, e não ficar bloqueado nas suas limitações.

Quanto à adequação dos conteúdos da formação inicial à realidade prática do magistério, Esteve defende a ideia de que a formação inicial deve "partir dos estudos realizados sobre os problemas que mais afetam os professores iniciantes quando, após abandonar as instituições de formação inicial, deparam com os problemas reais do magistério" (1999, p.129). Trata-se de estudar e antecipar os possíveis conflitos que os recém-formados encontrarão no exercício da docência. E isso se faz cada vez mais premente, ainda mais em tempo em que a docência, sua atuação e formação precisa ser

\section{Como referenciar este artigo:}

FÁVERO, A. A.; AGOSTINI, C. C.; RIGONI, L. M. Mal-estar docente e políticas de formação pedagógica. Revista Pedagógica, v. 23, p. 1-27, 2021. 
continuamente reformulada em função de uma realidade cada vez mais plástica e dinâmica.

No atual contexto, esse aspecto se mostra ainda mais tangível, já que a realidade destoa da prática comumente aplicada a formação inicial tradicional dos docentes. Como a mudança pandêmica e inserção do ensino remoto, por meio digital, aspectos da atuação docente foram modificados, indicando mudanças profundas na sua formação inicial. Não nos referimos aqui apenas nas questões de utilização de meios e ferramentas tecnológicas, mas também em relação a modificação da relação professor-aluno, a maneira com o professor planeja suas aulas, os momentos de interação pedagógica, os critérios para estabelecer as prioridades formativas. A pandemia trouxe a necessidade de reanálise da formação docente em relação a definição dos elementos e da experiência que compõe o trabalho do docente, principalmente porque a forma construída não se refere a uma simples transposição de atividades do meio presencial para o digital. O objeto e os meios tiveram que ser necessariamente redefinidos, e muitas vezes, a cargo do docente, sem uma formação correspondente. (SOUZA, et al, 2021).

As novas formas de interação humana em tempos pandêmicos demostram a necessidade de adequação da formação, a fim de diminuir o mal-estar docente que pode ser encontrado a partir do contrataste entre a formação inicial e a realidade cotidiana de uma sala de aula reestruturada e modificada em seus elementos mais profundos. $E$ isso perpassa a necessidade de uma formação inicial condizente e de um aspecto continuado no decorrer da prática. No entanto, é certo que esse caminho não deve ser trilhado de forma isolada pelo professor, é preciso pensar, planejar e dar destaque efetivo a necessidade e importância dessa formação.

Da mesma forma que, para haver mudanças, requer-se que, dentro do âmbito escolar, a gestão seja democrática, procurando realizar um trabalho de participação efetiva dos educadores, para que se sintam parte do processo do desenvolvimento do ensino. Em sendo a gestão um "processo pelo qual se mobiliza e coordena o talento humano, coletivamente organizado, de modo que as pessoas, em equipe, possam promover resultados desejados." (LUCK, 2010, p.96), a relação desse conceito com as políticas de

\section{Como referenciar este artigo:}

FÁVERO, A. A.; AGOSTINI, C. C.; RIGONI, L. M. Mal-estar docente e políticas de formação pedagógica. Revista Pedagógica, v. 23, p. 1-27, 2021. 
formação pedagógica como possibilidade de enfrentar o mal-estar docente se torna uma correlação necessária, principalmente a fim de promover segurança ao docente em relação a sua atuação, consciente e fundamentada em uma formação sólida.

Um corpo docente bem formado e motivado torna-se um elemento essencial para que haja um ensino de qualidade oferecido nos estabelecimentos escolares, ou em qualquer outro ambiente que possibilita processos de ensino e de aprendizagem. Portanto, é imprescindível continuar melhorando as condições de trabalho para o exercício docente saudável e para que a docência seja um atrativo profissional. O professor torna-se vulnerável às manifestações de estresse, quando às condições sociais, econômicas, tecnológicas e psicológicas são desfavoráveis para o exercício de sua profissão. A própria lógica neoliberal trabalha para contribuir com o desprestígio social, baixos salários, precarização das condições de trabalho, analfabetismo digital, insegurança e agressões verbais que são fatores que produzem a vulnerabilidade docente. Tal vulnerabilidade pode ser melhor enfrentada se houver uma gestão democrática que consiga refletir sobre tais problemáticas que os professores vivenciam diariamente, e sabiam promover espaços democráticos de diálogo para que coletivamente seja possível planejar estratégia de enfrentamento dessas manifestações de estresse, a fim de sensibilizar a sociedade sobre as condições de vida que os professores enfrentam no cotidiano escolar.

Da mesma forma que é fundamental que cada futuro educador vá realizando, durante o seu processo de formação, um conhecimento de si mesmo, de suas reações diante dos desafios da docência, dos problemas derivados da organização do trabalho de sala de aula e da atividade de ensino e aprendizagem e, com isso, consiga evitar o mal-estar docente. Nesse sentido, "valorizar o trabalho docente por meio da formação continuada é compreender que as práticas do professor são transformadoras" (MATOS, GROSCH, DRESCH, 2020, p.17) e indispensáveis ao sucesso educacional e a prevenção do mal-estar. Não se trata de tarefa fácil, no entanto, é primordial em tempos como os nossos.

\section{CONSIDERAÇÕES FINAIS}

Como referenciar este artigo:

FÁVERO, A. A.; AGOSTINI, C. C.; RIGONI, L. M. Mal-estar docente e políticas de formação pedagógica. Revista Pedagógica, v. 23, p. 1-27, 2021. 
Como visto, na contemporaneidade, muitos profissionais docentes não se satisfazem com a carga horária devido a desvalorização na remuneração, e acabam se sobrecarregando, tendo desconfortos, e/ou não sabendo lidar com situações cotidianas decorrentes do cansaço. Além disso, novas e diversas situações estão chegando à porta e ao interior das escolas, e o professor é cobrado pelos pais, pela sociedade, pelos profissionais de saúde, para dar conta de um universo de exigências, das quais nem sempre ele está preparado para enfrentar. Com o passar do tempo esses problemas se acumulam e geram estresses, mal-estar, doenças crônicas, perturbações psíquicas, esgotamento emocional, em casos mais graves, a desistência da profissão.

Os reflexos da síndrome na saúde física e mental ainda são ignorados ou negados por muitos. Paliativos de formação continuada focada em estratégias do "me ame, me abrace, me acolha" denunciadas por Fávero e Esquinsani (2011, p.6) não são suficientes para enfrentar o mal-estar docente, pois muitos professores continuam trabalhando até chegar ao limite de suas energias ou desistir da profissão. É o mal-estar, apontado por Freud (1997), como um mal e projeto da modernidade de Rouanet (1993) que corrompe a energia docente e impede que o mesmo realize seu trabalho de forma satisfatória, que lhe traga alegria, dignidade e autorrealização, como refere Esteve (1999) e os demais autores apresentados na mesma linha de argumentação. No entanto, o diagnóstico do mal-estar docente e as possibilidades do seu enfrentamento necessitam de políticas pedagógicas de formação inicial e continuada adequadas, realistas e proativas que não se reduzem a forma empresarial de educação como denunciam os estudos de Fávero; Tonieto; Consaltér (2020) Fávero; Pires; Consaltér (2020) e Fávero e Trevisol (2020).

Sendo assim, a partir da investigação realizada, foi possível concluir que há muita dificuldade para lidar com o mal-estar docente gerado pelas situações na atualidade. Porém, isso pode ser amenizado se aliado a forças e atitudes conscientes, tanto da parte dos docentes como da gestão, incluindo políticas públicas de formação. Infelizmente a realidade nos mostra que possivelmente o mal-estar não terá uma pronta resolução, pois depende de ações que sejam capazes de sensibilizar toda comunidade escolar e todos os sujeitos envolvidos possam perceber a importância da educação e do papel do profissional

\section{Como referenciar este artigo:}

FÁVERO, A. A.; AGOSTINI, C. C.; RIGONI, L. M. Mal-estar docente e políticas de formação pedagógica. Revista Pedagógica, v. 23, p. 1-27, 2021. 
Revista do Programa de Pós-Graduação em Educação da Unochapecó ISSN 1984-1566 (on-line) ISSN 1415-8175 (impressa)

que a conduz. É preciso uma desmistificação e uma compreensão de como o mal-estar docente está sendo vivenciado em nossa sociedade, quais seus sintomas, suas manifestações, seus efeitos colaterais e com isso pensar alternativas de formação aos professores para que possam se conscientizar subjetivamente e de forma coletiva de que é necessário lutar por melhores condições de trabalho, de valorização da profissão docente e na qualificação de sua formação.

\section{REFERÊNCIAS}

ALVES, Lynn. Educação Remota: entre a ilusão e a realidade. Interfaces Científicas Educação, v.8, 2020, p.348-365. Disponível em: https://periodicos.set.edu.br/educacao/article/view/9251. Acesso em: 13 jul. 2021.

CODO, Wanderley (coord.). Educação: carinho e trabalho. 4. ed. Petrópolis, Vozes, 2006.

CONSALTÉR, Evandro; FÁVERO, Altair Alberto. Elementos qualificadores da investigação científica no campo das políticas educacionais. Educação \& Formação, Fortaleza, v. 4, n. 1, p. 148-163, 2019. Disponível em:

https://revistas.uece.br/index.php/redufor/article/view/850. Acesso em: 20 abr. 2021.

CONSALTÉR, Evandro; FÁVERO, Altair Alberto. Diálogos e reflexões sobre formação de professores: possibilidades de superar o mal-estar docente. Revista da Faculdade de Educação da UFMT, v.34, ano 19, n.2, p.12-134, jul./dez., 2020. Disponível em:

https://periodicos.unemat.br/index.php/ppgedu/article/view/5152. Acesso em 20 abr. 2021.

CURI, Fabiano. Sob pressão. Revista Educação, São Paulo, Segmento, ano 10, n.119, mar. 2007, p.30-37.

DOMENCINI. Thiago. "É cruel”: professores encaram aulas virtuais com 300 alunos e demissões por 'pop-up' na tela. EI PAÍS BRASIL. Seção Agência Pública. Publicada em 22 set 2020. Disponível em: https://brasil.elpais.com/brasil/2020-09-23/e-cruel-professoresencaram-aulas-virtuais-com-300-alunos-e-demissoes-por-pop-up-na-tela.html. Acesso em 07 fev 2021.

ESTEVE, José Manuel. O mal-estar docente: a sala de aula e a saúde dos professores. Bauru: EDUSC, 1999.

FÁVERO, Altair Alberto. Desafios teórico-metodológicos da avaliação nos processos educativos. Revista Roteiro, v. 40, p. 85-100, 2015. Disponível em:

https://portalperiodicos.unoesc.edu.br/roteiro/article/view/9199. Acesso em: 21 abr. 2021.

Como referenciar este artigo:

FÁVERO, A. A.; AGOSTINI, C. C.; RIGONI, L. M. Mal-estar docente e políticas de formação pedagógica. Revista Pedagógica, v. 23, p. 1-27, 2021. 
FÁVERO, Altair Alberto; TONIETO, Carina. Educar o educador: reflexões sobre formação docente. Campinas: Mercado de Letras, 2020.

FAVERO, Altair; CENCI, Ângelo; DALBOSCO, Cláudio. A formação cultural como exigência para a formação docente: aproximações a partir das concepções filosófico-educativas de Adorno. In: KUIAVA, E. et al (org.). Filosofia, formação docente e cidadania. Ijuí: Unijuí, 2008, p.107-126.

FÁVERO, Altair Alberto. Políticas de Formação Pedagógica: possibilidades de superar o mal-estar docente. In: CENCI, Ângelo Vitório, DALBOSCO, Cláudio Almir; MÜHL, Eldon Henrique (org.). Sobre Filosofia e Educação: Racionalidade, diversidade e formação pedagógica. Passo Fundo: Ed. Universidade de Passo Fundo, 2009.

FÁVERO, Altair Alberto; TONIETO, Carina; CONSALTÉR, Evandro. O neoliberalismo pedagógico como produto do sujeito empresarial: ameaças à democracia educacional. Currículo sem Fronteiras, v. 20, n 1 - jan./abr. 2020. Disponível em: https://www.curriculosemfronteiras.org/vol2oiss1articles/favero-tonieto-consalter.pdf. Acesso em: 21 abr. 2021.

FÁVERO, Altair Alberto; PIRES, Daniela de Oliveira; CONSALTÉR, Evandro. Escola conveniada ou charter school? Uma abordagem sobre termo de colaboração entre prefeitura e o terceiro setor para oferta da educação básica em Porto Alegre. Revista Espaço Pedagógico, v.27, n.1, jan./abr. 2020. Disponível em: http://seer.upf.br/index.php/rep/article/view/10577. Acesso em: 21 abr. 2021.

FÁVERO, Altair Alberto; TREVISOL, Márcio Giusti. Quando a educação se torna um negócio: ideologia neoliberal na educação e a cristalização do novo senso comum pedagógico. Educação Unisinos, v.24, p.1-19, 2020. Disponível em:

http://revistas.unisinos.br > viewFile > edu.2020.241.18. Acesso em: 21 abr. 2021.

FÁVERO, Altair; ESQUINSANI, Rosimar. Me ame, me abrace, me acolha! saberes docentes e políticas de formação continuada. Revista contrapontos - Eletrônica, v.11, n.1, p.6-13, jan-abr, 2011.

FREUD, Sigmund. O mal-estar na civilização. Rio de Janeiro: Imago, 1997.

GENTILE, Paola. A educação, vista pelos olhos do professor. Revista Nova Escola, São Paulo, Editora Abril, ano XXII, n.207, novembro de 2007, p.32-39.

JAEGER, Werner. Paidéia: a formação do homem grego. São Paulo: Martins Fontes, 1989.

KANT, E. Sobre a pedagogia. Piracicaba: Unimep, 2004.

Como referenciar este artigo:

FÁVERO, A. A.; AGOSTINI, C. C.; RIGONI, L. M. Mal-estar docente e políticas de formação pedagógica. Revista Pedagógica, v. 23, p. 1-27, 2021. 
KANT, Immanuel. Textos seletos. Trad. Raimundo Vier. Petrópolis: Vozes, 1985.

LUCK, Heloísa. Liderança em Gestão Escolar. 6.ed. Petrópolis, Rio de Janeiro: Vozes, 2010.

MATOS, Gislaine Aparecida; GROSCH, Maria Selma; DRESCH, Jaime Farias. Formação continuada de professores: perspectivas e contradições epistemológicas recorrentes na elaboração de documentos oficiais da educação. Revista Pedagógica, Chapecó, v. 22, p. 119, 2020. Disponível em:

https://bell.unochapeco.edu.br/revistas/index.php/pedagogica/article/view/4746. Acesso em: 27 abr. 2021.

NÓVOA, António. Formação de professores e trabalho pedagógico. Lisboa: Educa, 2002.

OLIVEIRA, Eloiza da Silva G. O "mal-estar docente" como fenômeno da modernidade: os professores no país das maravilhas. Ciências \& Cognição, ano 3, v. 07, 2006.

ROUANET, Sergio P. Mal-estar na modernidade. São Paulo: Campanhia das Letras, 1993.

SACRISTÁN, J. G. Consciência e ação sobre a prática como libertação profissional dos professores. In: NÓVOA, A. Profissão Professor. Porto: Porto Editora, 1999.

SOUZA, Katia Reis de et al. Trabalho remoto, saúde docente e greve virtual em cenário de pandemia. Revista Trabalho, educação e saúde, Rio de Janeiro, v. 19, jan. 2021. Disponível em <http://www.scielo.br/scielo.php?script=sci_arttext\&pid=S1981-

77462021000100401\&lng=pt\&nrm=iso>. Acesso: em 23 abr. 2021.

Enviado em: 28-04-2021

Aceito em: 21-07-2021

Publicado em: 05-08-2021

Como referenciar este artigo:

FÁVERO, A. A.; AGOSTINI, C. C.; RIGONI, L. M. Mal-estar docente e políticas de formação pedagógica. Revista Pedagógica, v. 23, p. 1-27, 2021. 